\title{
Unforeseeable presentation of Chryseobacterium indologenes infection in a paediatric patient
}

\author{
Geethalakshmi Srinivasan', Swapna Muthusamy', Vinod Raveendran', Noyal Mariya Joseph² \\ and Joshy Maducolil Easow ${ }^{1 *}$
}

\begin{abstract}
Background: We report for the first time a case of community acquired Chryseobacterium indologenes soft tissue infection in an immunocompetent patient.

Case presentation: A 11 year female child, from South-Asia of Indian origin presented with fever, pain and swelling in right leg for 3 days with no significant past history. Incision and drainage was done and pus was sent for culture and sensitivity. Radiological investigation showed subtle irregular soft tissue density. Pus culture grew multidrug resistant C. indologenes.
\end{abstract}

Conclusion: Though of low pathogenicity, our case emphasises its unpredictable nature and the need to determine minimum inhibitory concentration breakpoints for therapy.

Keywords: Case report, Cellulitis, Chryseobacterium indologenes, Soft-tissue infection

\section{Background}

Previously known as Flavobacterium, the genus Chryseobacterium comprising six species are non-glucose fermenting bacilli. Chryseobacterium indologenes species was first isolated in 1993 from tracheal aspirate of a patient complicated with ventilator associated pneumonia. The clinical significance of the infections due to C. indologenes is poorly studied as not many cases are reported in literature and is also a rare human pathogen. Commonly seen in the environment, these are known to cause a spectrum of infections usually in hospitalized and immunocompromised patients, and in infants. Here we describe a case of $C$. indologenes infection in an immunocompetent child.

\section{Case presentation}

A 11 year old female child from South-Asia of Indian origin, presented to the orthopaedics department with

\footnotetext{
*Correspondence: dr.jmeasow@gmail.com

${ }^{1}$ Department of Microbiology, Sri Venkateshwaraa Medical College

Hospital and Research Centre, Ariyur, Puducherry 605 102, India

Full list of author information is available at the end of the article
}

complaints of fever, non-traumatic pain and swelling in the right leg for about 3 days. There was no significant past history. She was septic and was noted to have a diffuse swelling over the upper third of right leg with skin erythema, warmth and tenderness. No discharging sinuses were noted. Blood investigations showed a raised white cell count and marginally increased erythrocyte sedimentation rate (ESR). Rest of the haematological and biochemical markers were within normal limits. Blood sample was sent for culture and sensitivity which showed no growth. Anteroposterior and lateral views of plain radiograph of the right leg showed normal tibia and fibula with subtle irregular altered soft tissue density in the lateral aspect of the mid third of the leg (Fig. 1). Incision and drainage was performed the following day under general anaesthesia. Thick purulent discharge was drained and about $5 \mathrm{ml}$ of the discharge was sent for culture and sensitivity. The wound was left open and dressed appropriately (Table 1 ).

Gram staining of the purulent material showed numerous pus cells and gram negative bacilli. Inoculation in blood agar showed dark yellow pigmented colonies 


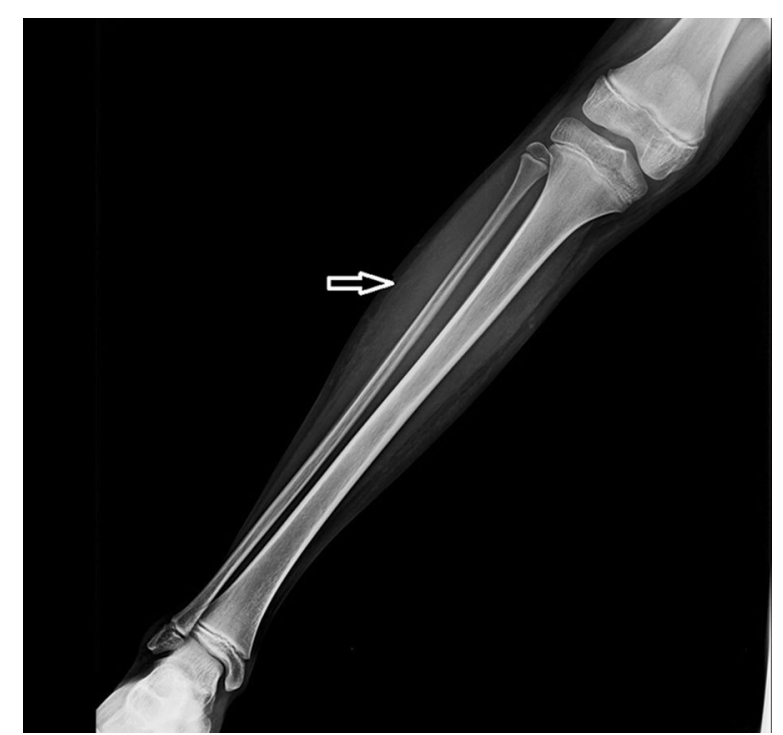

Fig. 1 Plain radiograph anteroposterior projection demonstrating patchy irregular increased soft tissue densities in the lateral aspect of the middle third of the right leg as marked by the arrow

with no hemolysis (Fig. 2). On nutrient agar yellow pigmented colonies were seen and were noticed to turn to red when $10 \%$ potassium hydroxide $(\mathrm{KOH})$ was added on to the culture (Fig. 3). It did not grow in Mac Conkey agar. The isolate was non-motile, catalase and oxidase positive, indole positive, methyl red negative and VogesProskauer's negative. Urea was not hydrolysed and citrate was not utilized. On triple sugar iron agar, glucose was utilised with gas production. The organism was identified by both conventional method and VITEK-2 systems version: 07.01 as C. indologenes.

Genus was presumptively identified as Chryseobacterium after $24 \mathrm{~h}$ and genus confirmation, species identification and sensitivity results were available in $48 \mathrm{~h}$. The minimum inhibitory concentration (MIC) values by VITEK-2 system are in Table 2.

Our isolate was susceptible to imipenem and resistant to meropenem and doripenem. Chryseobacterium species are intrinsically resistant to most beta lactams including carbapenems due to the production of chromosomally mediated metallobetalactamases (MBL). The isolate was a MBL producer which was confirmed by double disk diffusion method with ethylene diamine tetraacetic acid (EDTA).

Patient was empirically started on parenteral cefotaxime, metronidazole and gentamicin, was changed over to intravenous ceftazidime $1 \mathrm{~g}$ twice daily and metronidazole infusion $500 \mathrm{mg}$ thrice daily for 5 days based on the sensitivity report following which significant clinical improvement was noted. Subsequently secondary closure was done 10 days later. The wound healed well and the patient was discharged on oral antibiotics with follow up. Consent for publication was obtained from the patient's parent.

\section{Discussion}

Infection due to C. indologenes in humans is a rare occurrence and is usually nosocomial. These are mainly found in soil, plants, water and foodstuffs. They are not found in

Table 1 Timeline of case management

\begin{tabular}{|c|c|c|}
\hline Time & Process followed & Observation and management \\
\hline \multirow[t]{6}{*}{ Day 1} & History & Fever, pain and swelling for 3 days \\
\hline & Physical examination & Swelling with erythema, warmth and tenderness \\
\hline & Blood count, erythrocyte sedimentation rate & $\begin{array}{l}\text { Raised white cell count } \\
\text { Marginally elevated erythrocyte sedimentation rate }\end{array}$ \\
\hline & X-ray & $\begin{array}{l}\text { Normal tibia and fibula with subtle irregular altered soft tissue density in the lateral } \\
\text { aspect of the mid-third of the leg }\end{array}$ \\
\hline & Blood culture & No growth after 7 days of incubation \\
\hline & Treatment & Patient was empirically given parenteral cefotaxime, metronidazole and gentamicin \\
\hline \multirow[t]{3}{*}{ Day 2} & Incision and drainage under general anaesthesia & Thick purulent discharge was obtained and sent for culture and sensitivity \\
\hline & Gram stain & Plenty of pus cells and gram negative bacilli were seen \\
\hline & Culture & On incubation \\
\hline Day 3 & Genus identification by conventional method & $\begin{array}{l}\text { Chryseobacterium spp. } \\
\text { Subjected for VITEK-2 identification and antibiotic sensitivity testing }\end{array}$ \\
\hline Day 4 & Species identification by conventional and VITEK-2 & $\begin{array}{l}\text { C. indologenes } \\
\text { Minimum inhibitory concentration values by VITEK-2 as in Table } 2\end{array}$ \\
\hline Day 5 & Switching of antibiotics & $\begin{array}{l}\text { Cefotaxime was changed over to ceftazidime } \\
\text { Gentamicin was discontinued }\end{array}$ \\
\hline Day 5-12 & Local examination & Wound was healing well, secondary closure done and patient was discharged \\
\hline
\end{tabular}




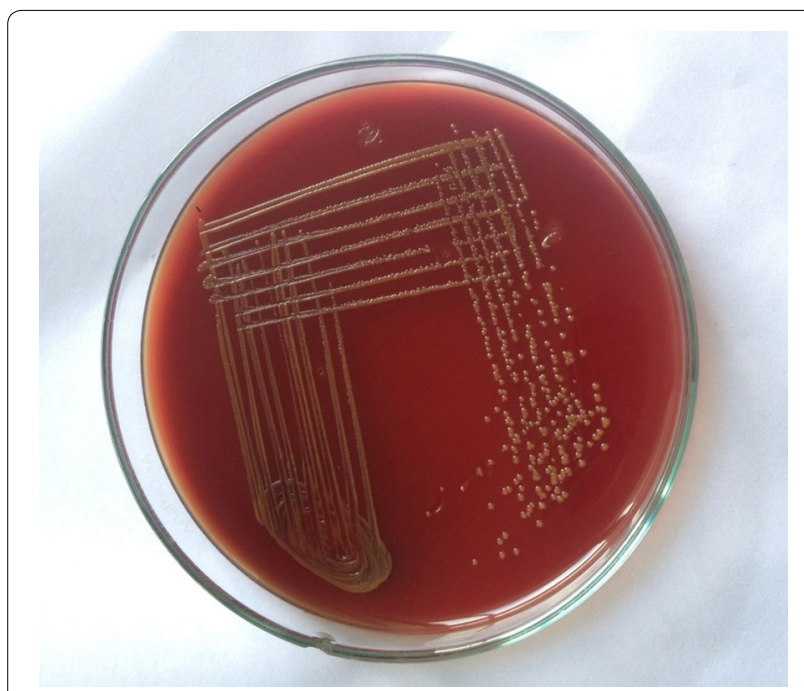

Fig. 2 Blood agar showing non-haemolytic yellow pigmented colonies of $\mathrm{C}$. indologenes

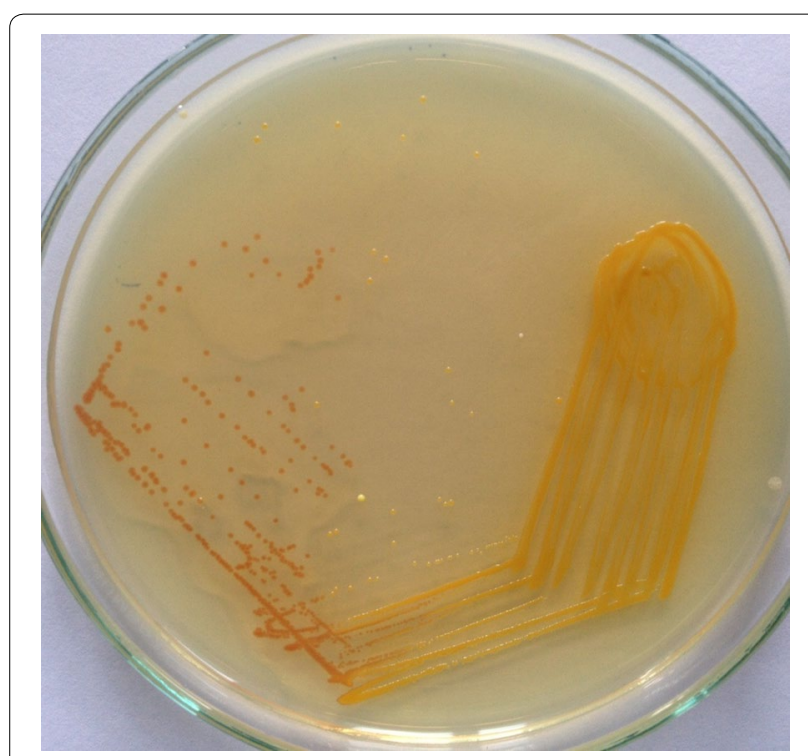

Fig. 3 Yellow pigmented colonies of C. indologenes turning to red upon addition of $10 \%$ potassium hydroxide

human flora. Within the hospital premises, they exist in water systems and wet surfaces and can survive in chlorinated water [1].

Chryseobacterium species are gram-negative, aerobic, non-motile, oxidase positive, catalase positive, indole positive, producing a distinct yellow orange pigment due to production of flexirubin. Indole was produced in tryptophan broth. The genus Chryseobacterium belongs to the family Flavobacteriaceae. The commonly isolated species includes C. meningosepticum, C. multivorum, $C$. odoratum, C. breve and group IIb Chryseobacterium species which includes $C$. indologenes and C. gleum. Of these C. meningosepticum is the most pathogenic causing neonatal meningitis [2].

Chryseobacterium infections are frequently associated with the presence of indwelling devices like intravascular catheters etc., in immunocompromised patients or in patients on long-term broad-spectrum antibiotics. Factors influencing the development of Chryseobacterium infection include a suitable entry port, invasive procedures, neutropenia, production of biofilm on foreign materials, prolonged use of antibiotics and immunodeficiency $[3,4]$. Infections associated with Chryseobacterium species include bacteremia, wound sepsis, indwelling device associated infections, ocular infections and intra-abdominal infections. In our patient it was associated with cellulitis, soft tissue infection and abscess formation. They are usually isolated from clinical specimens but rarely from blood as were in our case [4].

Most of the $C$. indologenes infections described in literature were hospital acquired and were seen in patients with underlying debilitating diseases [4-9]. Mostly our isolate is community acquired, as the sample grew Chryseobacterium from pus collected intraoperatively on the second day of admission. During the above said period, environmental surveillance samples did not grow Chryseobacterium.

Interestingly our patient was not immunosuppressed or was on any long term antibiotics or with indwelling devices, making this case unusual in presentation. Douvoyiannis et al. [10] had reported the first case of $C$. indologenes in a 33 day old infant in 2010. Hendaus et al. [11] reported the second case of $C$. indologenes infection from healthy newborn in 2013. Ours would be the third case of $C$. indologenes infection reported from an immunocompetent paediatric patient.

Not much data is available in literature on the choice of appropriate antibiotic for empirical treatment in $C$. indologenes infections [12]. This uncertainty is attributed to the wide spectrum of antimicrobial resistance, lack of gold standard susceptibility testing, unpredictable nature and non-establishment of MIC breakpoints for these organisms [13]. Further, biofilm and proteases production by $C$. indologenes species reduces its antimicrobial susceptibility [14]. Based on the results of SENTRY antimicrobial surveillance program during 1997-2001, the highest prevalence of Chryseobacterium was seen among the elderly. The most appropriate antibiotics that can be used for treating Chryseobacterium infections are newer fluoroquinolones (MIC 90-1 $\mu \mathrm{g} / \mathrm{ml}$ ) followed by rifampin (MIC 90-2 $\mu \mathrm{g} / \mathrm{ml}$ ). C. indologenes isolates showed adequate susceptibilities to trimethoprim-sulfamethoxazole, ciprofloxacin and piperacillin-tazobactam [15]. Variable 
Table 2 Minimum inhibitory concentration values by VITEK-2 system

\begin{tabular}{lll}
\hline Antibiotic & $\begin{array}{l}\text { Minimum inhibitory } \\
\text { concentration value } \\
(\boldsymbol{\mu g} / \mathbf{m l})\end{array}$ & Interpretation \\
\hline Gentamicin & $\geq 16$ & Resistant \\
Amikacin & $\geq 64$ & Resistant \\
Ceftazidime & 4 & Susceptible \\
Piperacillin-tazobactam & 64 & Intermediate \\
Cefaperazone-sulbactam & 32 & Intermediate \\
Imipenem & 1 & Susceptible \\
Meropenem & $\geq 16$ & Resistant \\
Doripenem & $\geq 8$ & Resistant \\
Minocycline & $\leq 1$ & Susceptible \\
Levofloxacin & 0.25 & Susceptible \\
Ciprofloxacin & $\leq 0.25$ & Susceptible \\
Cotrimoxazole & $\leq 20$ & Susceptible \\
Aztreonam & $\geq 64$ & Resistant \\
\hline
\end{tabular}

susceptibility to vancomycin has been reported in literature [16].

Chryseobacterium indologenes is invariably resistant to aminoglycosides, shows varying degree of resistance to carbapenems, cephalosporins, piperacillin-tazobactam and are susceptible to fluroquinolones and cotrimoxazole. Based on the sensitivity pattern reported in SENTRY [15] and other literatures $[9,10,17]$, there was no evident difference for community acquired isolates as compared with hospital acquired strains.

In this study, the isolate was resistant to meropenem and susceptible to imipenem by VITEK-2 systems. This could be due to different mechanisms involved in imipenem and meropenem resistance. Meropenem resistance is due to efflux systems and imipenem resistance is by porin mutations. Over expression of MexAB-OprM, an efflux system pumps out meropenem but not imipenem [18]. As the isolate was confirmed to be a MBL producer by imipenem-EDTA double disc diffusion test, all the carbapenems were reported as resistant for therapeutic purpose.

Disk diffusion methods are not reliable and thus susceptibility testing by broth micro dilution method should be performed [19].

\section{Conclusion}

Listed as one of the nosocominal infections, C. indologenes infections known for its rare and sporadic incidence can cause potentially serious infections in humans. As described they can cause significant infections in immunocompetent individuals as well. More extensive and long term studies are required to understand the demographics, pathogenicity, virulence factors, arbitrary antimicrobial resistance and appropriate antimicrobial therapy.

\section{Abbreviations}

ESR: erythrocyte sedimentation rate; EDTA: ethylene diamine tetraacetic acid; $\mathrm{MBL}$ : metallo beta-lactamase; MIC: minimum inhibitory concentration; $\mathrm{KOH}$ : potassium hydroxide.

\section{Authors' contributions}

GS, SM, VR - Collected data and involved in preparation of manuscript. NMJ, JME-Finalising the manuscript. All authors read and approved the final version of the manuscript.

\section{Author details}

${ }^{1}$ Department of Microbiology, Sri Venkateshwaraa Medical College Hospital and Research Centre, Ariyur, Puducherry 605 102, India. ${ }^{2}$ Department of Microbiology, JIPMER, Puducherry 605 005, India.

\section{Acknowledgements}

We acknowledge the faculty in Departments of Orthopedics and Radiodiagnosis, Sri Venkateshwaraa Medical College Hospital and Research Center Ariyur, Pondicherry for their kind cooperation during data collection.

\section{Competing interests}

The authors declare that they have no competing interests.

Availability of data and materials

All the data are included in the manuscript.

\section{Consent to publish}

Written informed consent was obtained from the patient's legal guardian for publication of this Case Report and any accompanying images. A copy of the written consent is available for review by the Editor-in-Chief of this journal.

Received: 11 September 2015 Accepted: 3 April 2016

Published online: 12 April 2016

\section{References}

1. Calderón G, García E, Rojas P, García E, Rosso M, Losada A. Chryseobacterium indologenes infection in a newborn: a case report. J Med Case Rep. 2011;5:10. doi:10.1186/1752-1947-5-10

2. Lin YT, Jeng YY, Lin ML, Yu KW, Wang FD, Liu CY. Clinical and microbiological characteristics of Chryseobacterium indologenes bacteremia. J Microbiol Immunol Infect. 2010;43:498-505. doi:10.1016/ S1684-1182(10)60077-1.

3. Christakis GB, Perlorentzou SP, Chalkiopoulou I, Athanasiou A, Legakis NJ. Chryseobacterium indologenes non-catheter-related bacteremia in a patient with a solid tumor. J Clin Microbiol. 2005;43:2021-3. doi:10.1128/ JCM.43.4.2021-2023.2005.

4. Hsueh PR, Hsiue TR, Wu JJ, Teng LJ, Ho SW, Hsieh WC, et al. Flavobacterium indologenes bacteremia: clinical and microbiological characteristics. Clin Infect Dis. 1996;23:550-5.

5. Akay M, Gunduz E, Gulbas Z. Catheter-related bacteremia due to Chryseobacterium indologenes in a bone marrow transplant recipient. Bone Marrow Transplant. 2006;37:435-6. doi:10.1038/sj.bmt.1705261.

6. Cascio A, Stassi G, Costa GB, Crisafulli G, Rulli I, Ruggeri C, et al. Chryseobacterium indologenes bacteraemia in a diabetic child. J Med Microbiol. 2005;54:677-80. doi:10.1099/jmm.0.46036-0.

7. Hsueh PR, Teng L, Yang PC, Ho SW, Hsieh WC, Luh KT. Increasing incidence of nosocomial Chryseobacterium indologenes infections in Taiwan. Eur J Clin Microbiol Infect Dis. 1997;16:568-74.

8. Hsueh PR, Teng LJ, Ho SW, Hsieh WC, Luh KT. Clinical and microbiological characteristics of Flavobacterium indologenes infections associated with indwelling devices. J Clin Microbiol. 1996;34:1908-13.

9. Aydin Teke T, Oz FN, Metin O, Bayhan Gl, Gayretli Aydin ZG, Oguz M, et al. Chryseobacterium indologenes septicaemia in an infant. Case Rep Infect Dis. 2014;2014:270521. doi:10.1155/2014/270521. 
10. Douvoyiannis M, Kalyoussef S, Philip G, Mayers MM. Chryseobacterium indologenes bacteremia in an infant. Int J Infect Dis. 2010;14:e531-2. doi:10.1016/j.jijid.2009.06.015.

11. Hendaus MA, Zahraldin K. Chryseobacterium indologenes meningitis in a healthy newborn: a case report. Oman Med J. 2013;28:133-4. doi:10.5001/omj.2013.35.

12. Green BT, Nolan PE. Cellulitis and bacteraemia due to Chryseobacterium indologenes. J Infect. 2001;42:219-20. doi:10.1053/jinf.2001.0822.

13. Clinical and Laboratory Standards Institute (CLSI). Performance standards for antimicrobial susceptibility testing. In: 17th informational supplement. CLSI Document M100-S17. Wayne, PA: Clinical and Laboratory Standards Institute; 2007.

14. de Ferreira RS, Brandao FF, Lobo SM. Chryseobacterium indologenes infection: a case report. Rev Bras Ter Intensiva. 2010;22:96-8.

15. Kirby JT, Sader HS, Walsh TR, Jones RN. Antimicrobial susceptibility and epidemiology of a worldwide collection of Chryseobacterium spp: report from the SENTRY antimicrobial surveillance program (1997-2001). J Clin Microbiol. 2004;2004(42):445-8. doi:10.1128/JCM.42.1.445-448.
16. Bhuyar G, Jain S, Shah H, Mehta VK. Urinary tract infection by Chry seobacterium indologenes. Indian J Med Microbiol. 2012;30:370-2. doi:10.4103/0255-0857.99511.

17. Cunha V, Ferreira M, Fonseca A, Diogo J. Community-acquired Chryseobacterium indologenes in an immunocompetent patient. JMM Case Rep. 2014. doi:10.1099/jmmcr.0.000588.

18. Rodriguez-Martinez JM, Poirel L, Nordmann P. Molecular epidemiology and mechanisms of carbapenem resistance in Pseudomonas aeruginosa. Antimicrob Agents Chemother. 2009;53:4783-8. doi:10.1128/ AAC.00574-09.

19. Fraser $\mathrm{SL}$, Jorgensen $\mathrm{JH}$. Reappraisal of the antimicrobial susceptibilities of Chryseobacterium and Flavobacterium species and methods for reliable susceptibility testing. Antimicrob Agents Chemother. 1997;41:2738-41.

\section{Submit your next manuscript to BioMed Central and we will help you at every step:}

- We accept pre-submission inquiries

- Our selector tool helps you to find the most relevant journal

- We provide round the clock customer support

- Convenient online submission

- Thorough peer review

- Inclusion in PubMed and all major indexing services

- Maximum visibility for your research

Submit your manuscript at www.biomedcentral.com/submit

() Biomed Central 